Article

\title{
Structural Characterization of Mannoglucan from Dendrobium nobile Lindl and the Neuritogenesis-Induced Effect of Its Acetylated Derivative on PC-12 Cells
}

\author{
Can Jin 1,2,3, Zhenyun Du ${ }^{2,3}$, Liyan Lin ${ }^{1,2,3}$, Lishuang Zhou ${ }^{1,2,3}$, Saijuan Li ${ }^{1,2,3}$, Qin Liu ${ }^{2,3}$ \\ and Kan Ding 1,2,3,* \\ 1 School of Pharmacy, Zunyi Medical University, 201 Dalian Road, Zunyi 563003, China; \\ Can530037655@163.com (C.J.); linliyanglc@foxmail.com (L.L.); 17602129269@163.com (L.Z.); \\ 17602121570@163.com (S.L.) \\ 2 Glycochemistry and Glycobiology Lab, Shangshai Institute of Materia Medica, \\ Key Laboratory of Receptor Research, Chinese Academy of Sciences, $555 \mathrm{Zu}$ Chong Zhi Road, \\ Shanghai 201203, China; duzhenyunchina@163.com (Z.D.); liuqin@simm.ac.cn (Q.L.) \\ 3 University of Chinese Academy of Sciences, No.19A Yuquan Road, Beijing 100049, China \\ * Correspondence: dingkan@simm.ac.cn; Tel./Fax: +86-21-5080-6928
}

Received: 20 July 2017; Accepted: 22 August 2017; Published: 28 August 2017

\begin{abstract}
A water-soluble polysaccharide (JCS1) was isolated from the stems of Dendrobium nobile Lindl. JCS1 was structurally characterized using a combination of chemical and spectral analysis, including methylation analysis, partial acid hydrolysis, Fourier-transform infrared (FTIR) spectroscopy, gas chromatography (GC), GC-mass spectrometry (MS), and nuclear magnetic resonance (NMR) spectroscopy. The molecular weight was estimated to be $2.3 \times 10^{4}$ Da using high-performance gel permeation chromatography (HPGPC). The sugar composition analysis indicated it was composed of glucose, mannose, xylose, and arabinose in a 40.2:2.3:1.7:1.0 molar ratio. The structure analysis showed that JCS1 was a mannoglucan with a backbone consisting of $(1 \rightarrow 4)$-linked $\beta$-Man $p$ and $(1 \rightarrow 4)$-linked $\alpha$-Glc $p$ with branches at C- 6 of $(1 \rightarrow 4)$-linked $\alpha$-Glc $p$ residues. The branches were composed of T- $\alpha$-Glc $p, 1,4-\alpha-X y l p$, and T- $\alpha$-Araf. In vitro bioactivity tests revealed that the acetylated derivative of JCS1, YJCS1, induced neuritogenesis of PC-12 cells. These results demonstrate that YJCS1 might be a promising bioactive polysaccharide for development as a drug candidate for the possible prevention and treatment of neurodegeneration diseases.
\end{abstract}

Keywords: mannoglucan; polysaccharide; Dendrobium nobile Lindl; neuritogenesis; neurodegeneration disease

\section{Introduction}

Dendrobium nobile Lindl belongs to the orchid species and is widely distributed in Asia, including Thailand, Laos, Vietnam, and China [1,2]. It has been used as a medicinal and edible plant for thousands of years in China [2]. Its dried stems, the main medicinal part, have been studied for its "reinforcement" of body fluids, blood nourishment, promotion of saliva secretion, fever reduction, treatment of chronic gastritis, depression of cholesterol levels, and immunostimulation [2,3]. Recently, polysaccharides isolated from $D$. nobile have been demonstrated to possess immunostimulatory, antitumor, antioxidant, and hypoglycemic activities [3-6]. Attempts have been made to apply appropriate methods to modify the native polysaccharides to optimize their biological activities [7-13]. However, it is not clear whether acetylated modification of the native polysaccharide could induce neuritogenesis. In this paper, we 
report our determination of the structure of native polysaccharide obtained from $D$. nobile and the neuritogenesis-promoting effect of its acetylated derivative on PC-12 cells.

\section{Materials and Methods}

\subsection{Materials}

The dried stems of D. nobile were purchased from Dendrobium nobile Industrial Development Co., Ltd., (Guizhou, China). The purification medium Q Sepharose Fast Flow was purchased from GE Healthcare Life Science (Pittsburgh, PA, USA). The dialysis tubes with a molecular weight cutting off (MWCO) of 3500 Da were from Shanghai Green Bird Co (Shanghai, China). The different pullulans with known molecular weight (P-5, P-10, P-20, P-50, P-100, P-200, P-400, and P-800) were from Shodex Co., (Tokyo, Japan). Monosaccharide standards (mannose, rhamnose, glucuronic acid, galacturonic acid, glucose, galactose, xylose, arabinose, and fucose) were from Fluka (Buchs, Switzerland). Deuteroxide $\left(\mathrm{D}_{2} \mathrm{O}, 99.9 \% \mathrm{D}\right)$ was from CIL (Andover, MA, USA). 3-(4,5-Dimethylthiazol-2-yl)-2,5-diphenyl tetrazolium bromide (MTT) was from Sigma-Aldrich (Saint Louis, MO, USA). PC-12 cells were from American Type Culture Collection (ATCC, Manassas, VA, USA). All reagents were of analytical grade unless otherwise noted.

\subsection{Preparation of JCS1 and Its Acetylated Derivative}

\subsubsection{Preparation of JCS1}

The herbals of $D$. nobile $(2 \mathrm{~kg}$ ) were cut into $2 \mathrm{~cm}$ piece of stem and defatted by immersion in $95 \%$ ethanol $(40 \mathrm{~L})$ for twice, each for five days, at $25^{\circ} \mathrm{C}$. The ethanol extract were stirred once every $1 \mathrm{~h}$. Five days later, the herbal residues were immersed into $40 \mathrm{~L}$ of ethanol again to further defatted with stirring as aforementioned. After ethanol was removed, the ethanol-insoluble residues were air dried at $25^{\circ} \mathrm{C}$. Then the residues were extracted with boiling water $(40 \mathrm{~L})$ seven times, $4 \mathrm{~h}$ each time. After filtration, the extracts were concentrated to the volume of $4 \mathrm{~L}$ by heating at $100^{\circ} \mathrm{C}$ followed by dialysis with filter bag (cutoff is $5000 \mathrm{Da}$ ) against running tap water for two days. After the dialyzed extract solution was centrifuged ( $8000 \mathrm{rpm}$ ) for $5 \mathrm{~min}$, the supernatant was concentrated and precipitated with four volumes of $95 \%$ ethanol with vigorous stirring. After standing the mixture overnight, the mixture was centrifuged $(8000 \mathrm{rpm})$ for $5 \mathrm{~min}$, the precipitate was washed successively with absolute ethanol and acetone for three times, and then dried at $40{ }^{\circ} \mathrm{C}$ in an oven to obtain the crude polysaccharide, designated as JCS. JCS (10 g) was dissolved in $200 \mathrm{~mL}$ distilled water, and centrifuged $(8000 \mathrm{rpm})$ for $5 \mathrm{~min}$. The supernatant was fractionated using a Q Sepharose Fast Flow column $(0.98 \mathrm{~L})$ and eluted with $1.2 \mathrm{~L}$ of $0.1 \mathrm{M}$ sodium chloride $(\mathrm{NaCl})$ solution to obtain the target polysaccharide, JCS1.

\subsubsection{Preparation of Acetylated Derivative}

The JCS1 was acetylated using a previously described method [14]. Briefly, JCS1 (100 mg, dried under vacuum conditions overnight) was dissolved in $8 \mathrm{~mL}$ dimethyl sulfoxide (DMSO), stirred with a magnetic stirrer, and reacted for $24 \mathrm{~h}$ at room temperature to obtain a homogeneous solution. Then, $0.6 \mathrm{~mL}$ pyridine and $0.5 \mathrm{~mL}$ acetic anhydride was added sequentially to the reaction solution, the reaction was run for $2 \mathrm{~h}$ at $4{ }^{\circ} \mathrm{C}$, and then it was terminated by adding distilled water, followed by dialyzation and lyophilization to obtain the acetylated derivative, YJCS1.

The acetyl group and degree of substitution (DS) of YJCS1 were determined using a previously reported method [14]. The DS values were calculated as follows:

$$
\mathrm{DS}=1.62 \mathrm{M} /(43-0.42 M)
$$

where $M=$ acetyl group (\%, expressed as a percentage of the detected JCS1). 


\subsection{Homogeneity and Molecular Weight}

The homogeneity and molecular weight were determined using a high-performance gel permeation chromatography (HPGPC) method using an Agilent 1260 Series HPLC system (Santa Clara, CA, USA) with a tandem KS-804 and KS-802 (ID 8 mm and length $300 \mathrm{~mm}$, Shodex Co., Tokyo, Japan). The column temperature was at $40.0 \pm 0.1^{\circ} \mathrm{C}$. The mobile phase was $0.2 \mathrm{M} \mathrm{NaCl}$ run at a flow rate of $0.8 \mathrm{~mL} / \mathrm{min}$. All samples were prepared as $0.2 \%(w / v)$ solutions in the eluent, centrifuged, and then the supernatant was analyzed using a $20 \mu \mathrm{L}$ injection volume in each run [15].

\subsection{Monosaccharide Composition Analysis}

The monosaccharide composition was analyzed according to a previous method [15]. Briefly, samples $(2 \mathrm{mg})$ were dissolved in $2 \mathrm{~mL}$ water $\left(\mathrm{H}_{2} \mathrm{O}\right)$ and hydrolyzed with the same volume of $4 \mathrm{M}$ trifluoroacetic acid (TFA) in a sealed test tube at $110^{\circ} \mathrm{C}$ for $4 \mathrm{~h}$. The solution was repeatedly evaporated with methanol to completely remove the TFA under reduced pressure. The hydrolysate was dissolved in $2 \mathrm{~mL} \mathrm{H}_{2} \mathrm{O}$ and reduced with $50 \mathrm{mg}$ sodium borohydride $\left(\mathrm{NaBH}_{4}\right)$ for $3 \mathrm{~h}$ at room temperature while shaking the sealed test tube occasionally. The reduction reaction was neutralized with $25 \%$ acetic acid and evaporated with methanol to obtain a dry powder, which was further dried in an oven at $100{ }^{\circ} \mathrm{C}$ for $30 \mathrm{~min}$. Then, the dried residue was acetylated with $3 \mathrm{~mL}$ acetic anhydride $\left(\mathrm{Ac}_{2} \mathrm{O}\right)$ for $1.5 \mathrm{~h}$ at $100{ }^{\circ} \mathrm{C}$. After evaporating to dryness with toluene, the residue was extracted with chloroform $\left(\mathrm{CHCl}_{3}\right)$, washed three times with distilled $\mathrm{H}_{2} \mathrm{O}(1: 1, v / v)$, and the resulting alditol acetates were analyzed using gas chromatography (GC). The GC analysis was performed using a Shimadzu GC-14B instrument (Kyoto, Japan) with a 3\% OV-225-packed glass column $(3.2 \mathrm{~mm} \times 200 \mathrm{~cm})$. The detector was flame ionization detector (FID, Kyoto, Japan). The temperatures were 250 and $240{ }^{\circ} \mathrm{C}$ for injection and detection, respectively. The flow rate of the nitrogen carrier gas was $25 \mathrm{~mL} / \mathrm{min}$, and the column temperature was maintained at $210^{\circ} \mathrm{C}$.

\subsection{Methylation Analysis}

Using a previously reported method [16], the vacuum-dried polysaccharide (10 $\mathrm{mg})$ was methylated three to four times until the polysaccharide hydroxyl absorption in the infrared (IR) spectrum (Nujol) disappeared. Then, the methylated polysaccharide was hydrolyzed with $2 \mathrm{M}$ TFA at $110{ }^{\circ} \mathrm{C}$ for $4 \mathrm{~h}$, reduced with $\mathrm{NaBH}_{4}$, and finally acetylated to obtain the partially methylated alditol acetates, which were analyzed using GC-mass spectrometry (MS, HP-5 capillary column, $0.25 \mathrm{~mm} \times 30 \mathrm{~m}$, Santa Clara, CA, USA). The carrier gas was nitrogen, and the column temperature was gradually increased at $2{ }^{\circ} \mathrm{C} / \mathrm{min}$ from 140 to $250{ }^{\circ} \mathrm{C}$.

\subsection{Fourier Transform Infrared (FTIR) and Nuclear Magnetic Resonance (NMR) Analysis}

To determine the polysaccharide FT-IR spectra, the samples were first prepared in two forms. For example, the native and per-methylated polysaccharides were processed as potassium bromide (KBr) pellets and Nujol films, respectively. Furthermore, the FT-IR measurement (PerkinElmer 591B, Waltham, MA, USA) was performed in the frequency range of $4000-500 \mathrm{~cm}^{-1}$.

The ${ }^{1} \mathrm{H}$ NMR, $\left({ }^{1} \mathrm{H}\right)-{ }^{1} \mathrm{H}$ correlation spectroscopy (COSY) and ${ }^{13} \mathrm{C}$ NMR (heteronuclear single-quantum correlation [HSQC] and heteronuclear multiple-bond correlation [HMBC]) spectra were recorded at $25{ }^{\circ} \mathrm{C}$ using a Bruker AVANCE III NMR spectrometer (Karlsruhe, Germany) with acetone as the internal standard, conducted at 500 and $125 \mathrm{MHz}$, respectively. For the deuterium-exchange, the polysaccharides $(30 \mathrm{mg})$ were dissolved in $0.5 \mathrm{~mL} \mathrm{D}_{2} \mathrm{O}(99.9 \% \mathrm{D})$. Furthermore, 31.50 and $4.85 \mathrm{ppm}$ for the ${ }^{13} \mathrm{C}$ NMR (acetone) and ${ }^{1} \mathrm{H}$ NMR (HDO), respectively, were used as the references to calibrate the chemical shifts. 


\subsection{Partial Acid Hydrolysis}

The JCS1 $(100 \mathrm{mg})$ was dissolved in $0.05 \mathrm{M}$ TFA $(10 \mathrm{~mL})$, hydrolyzed at $100{ }^{\circ} \mathrm{C}$ for $1 \mathrm{~h}$, the resulting solution was evaporated to dryness, and then dialyzed for $48 \mathrm{~h}$. The collected retentate $(60 \mathrm{mg})$ was further hydrolyzed with $0.1 \mathrm{M}$ TFA $(6 \mathrm{~mL})$ at $100{ }^{\circ} \mathrm{C}$ for $1 \mathrm{~h}$. Homogeneity, molecular weight, and monosaccharide composition, as well as methylation and NMR analyses of the hydrolysates (JCS1 $0.1 \mathrm{~N})$, were performed.

\subsection{Bioactivity Test of Polysaccharide in PC-12 Cells}

The PC-12 cells (ATCC) were seeded into 12-well plates containing $50 \mu \mathrm{g} / \mathrm{mL}$ polylysine for $24 \mathrm{~h}$, and then they were cultured in Dulbecco's modified Eagle's medium (DMEM) containing 1.0\% horse serum and $0.5 \%$ fetal bovine serum (both serum are inactivated at $56{ }^{\circ} \mathrm{C}$ for $30 \mathrm{~min}$ before using) for $24 \mathrm{~h}$. Subsequently, varying concentrations of polysaccharide JCS1 and YJCS1 were added to the cell culture medium and incubated for $72 \mathrm{~h}$ while $25 \mathrm{ng} / \mathrm{mL}$ nerve growth factor (NGF, Invitrogen, Boston, MA, USA) was used as a positive control. The cell morphology was observed using an inverted fluorescent microscope (Olympus IX73, Tokyo, Japan), and the images were acquired at a magnification of $400 \times$. The experiments were performed in triplicate using duplicate wells.

\section{Results}

\subsection{Isolation, Purification, and Composition Analysis}

The crude polysaccharide JCS was obtained in $1.3 \%$ yield by boiling-water extraction from the dried stems of $D$. nobile, and further fractionated by anion-exchange chromatography on a $Q$ Sepharose Fast Flow column to give $0.1 \mathrm{M} \mathrm{NaCl}$ eluent JCS1 (yield 18.9\%). JCS1 was demonstrated to be a homogeneous polysaccharide by the presence of a symmetrical peak on HPGPC. The average molecular weight of JCS1 was estimated to be $2.3 \times 10^{4} \mathrm{Da}$. The results showed that JCS1 contained $6.6 \%$ protein using the Lowry method [17], and was shown to be free of uronic acid using the $m$-hydroxyl diphenyl method [18]. The sugar composition of JCS1 was determined using GC analysis. The results showed that JCS1 contained glucose, mannose, xylose, and arabinose in a molar ratio of 40.2:2.0:1.3:1.0.

\subsection{IR and Specific Rotation Analysis}

The previously reported method used for the analysis [14] showed that JCS1 was acetylated and named YJCS1. The IR spectra of JCS1 and its acetylated derivative YJCS1 are shown in Figure 1. Typical polysaccharide signals were observed in their IR spectra. Compared with JCS1, the hydroxyl stretching band at $3431.7 \mathrm{~cm}^{-1}$ of YJCS1 was obviously smaller. The new absorption signals that appeared at 1247.6 and $1736.9 \mathrm{~cm}^{-1}$, assigned as the $\mathrm{C}=\mathrm{O}$ stretching vibration, indicating that the acetylated modification of JCS1 was successful [19]. The specific optical rotation of JCS1 was estimated to be $115.3^{\circ}\left(c 1.0, \mathrm{H}_{2} \mathrm{O}\right)$. 


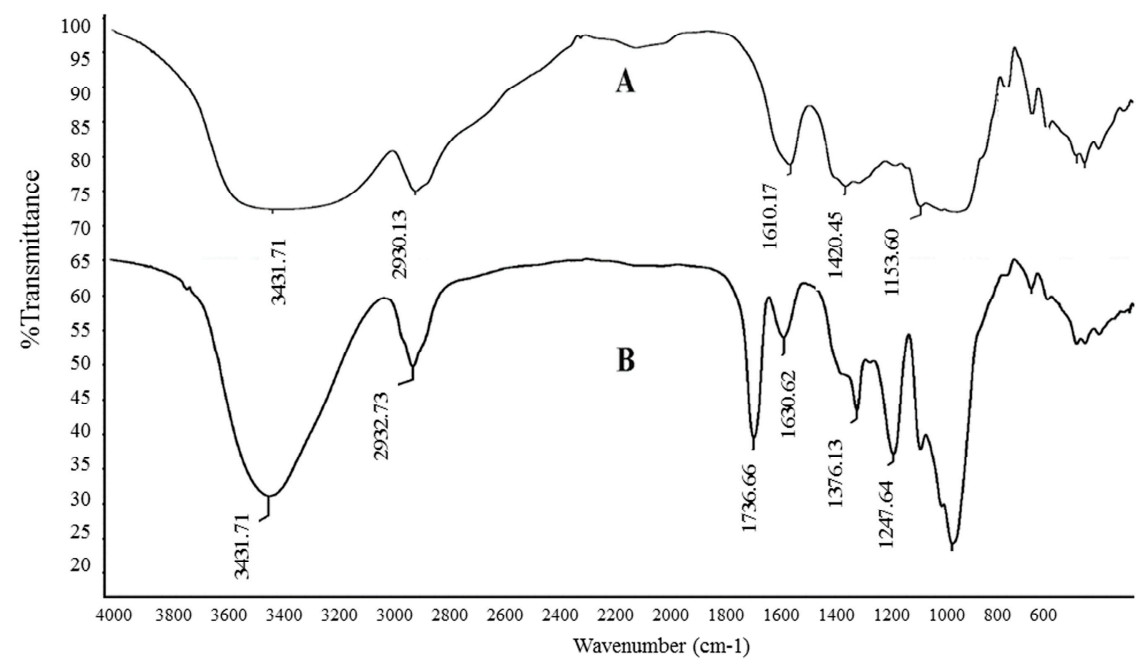

Figure 1. (A) Fourier transform infrared (FTIR) spectra of JCS1 and (B) acetylated derivative YJCS1.

\subsection{Linkage Type Analysis}

The analysis was performed according to a previous method [16]. The polysaccharide JCS1 (10 mg) was methylated four times after it was vacuum-dried. The JCS1 was completely methylated, hydrolyzed, reduced, and $O$-acetylated as partially methylated alditol acetates (PMAA), which were analyzed using GC-MS and the results are summarized in Table 1 . The results showed that this polysaccharide had six main glycosyl residues, which were 2,3,4,6-Me $\mathrm{Me}_{4}-\mathrm{Glc} p$,

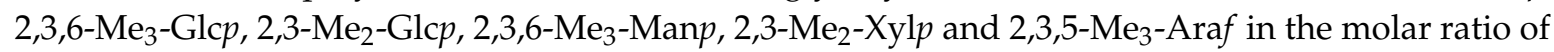
2.6:34.2:3.2:2.2:1.6:1.0. The results suggested that JCS1 might have a backbone, which at least consisted of $(1 \rightarrow 4)$-linked-Glc $p$ with branches at C-6 of $(1 \rightarrow 4)$-linked-Glcp.

Table 1. Linkage analysis of JCS1 polysaccharide and its degraded product JCS10.1N using gas chromatography (GC-MS).

\begin{tabular}{|c|c|c|c|}
\hline \multirow{2}{*}{ Methylated Sugars } & \multirow{2}{*}{ Linkages } & \multicolumn{2}{|c|}{ Molar Ratio \% } \\
\hline & & JCS1 & JCS10.1N * \\
\hline $2,3,6-\mathrm{Me}_{3}-\mathrm{Glc}$ & 1,4-Glcp & 34.2 & 17.8 \\
\hline 2,3,4,6-Me ${ }_{4}$-Glc & T-Glcp & 2.6 & 2.6 \\
\hline $2,3-\mathrm{Me}_{2}-\mathrm{Glc}$ & $1,4,6-$ Glcp & 3.2 & 3.0 \\
\hline 2,3,6- $\mathrm{Me}_{3}$-Man & 1,4-Manp & 2.2 & 2.3 \\
\hline $2,3-\mathrm{Me}_{2}-\mathrm{Xyl}$ & $1,4-\mathrm{Xyl} p$ & 1.6 & 0.6 \\
\hline 2,3,5-Me - -Ara & T-Araf & 1.0 & _ \\
\hline
\end{tabular}

* JCS10.1N was polysaccharide dialyzed retentate from JCS1 after it was partially hydrolyzed with 0.05 and $0.1 \mathrm{M}$ TFA, respectively.

\subsection{Partial Acid Hydrolysis and Structure Characterization of Degraded Polysaccharide}

To characterize the JCS1, it was partially hydrolyzed with 0.05 M TFA and dialyzed to obtain the retentate, which was further hydrolyzed with $0.1 \mathrm{M}$ TFA and dialyzed against water to provide the final retentate, named JCS10.1N. HPGPC analysis showed that JCS10.1N was homogeneous with a molecular weight of $15.5 \mathrm{kDa}$. The results of the monosaccharide composition analysis showed that JCS10.1N was composed of glucose, mannose, and xylose in a molar ratio of 40.1:2.2:1.0. It was methylated and analyzed using GC-MS, and the results are shown in Table 1. The results showed that the residues linkage types were 1,4-linked Glc $p(17.8 \%), 1,4,6$-linked Glc $p(3.0 \%), 1,4$-linked Man $p$ $(2.3 \%)$, and 1,4-linked Xylp (0.6\%), and T-linked $\alpha$-Glcp (2.6\%). Compared with the methylation analysis of the native JCS1 (Table 1), the T-linked $\alpha$-Araf vanished, which suggests that the Ara 
residues were sensitive to this mild acid. This indicates that Ara was probably located on the outer branches and that JCS1 has a $(1 \rightarrow 4)$-linked Man $p$ and $(1 \rightarrow 4)$-linked $\alpha$-Glc $p$ backbone with branches at the C- 6 of $(1 \rightarrow 4)$-linked $\alpha$-Glc $p$ residues.

\subsection{NMR Results}

The ${ }^{13} \mathrm{C}$ NMR spectra of JCS10.1N and JCS1 are shown in Figure 2A,B, respectively. In the ${ }^{13} \mathrm{C}$ NMR spectrum of JCS1, the anomeric signals of Glc, Man Xyl, and Ara were assigned and combined with the ${ }^{13} \mathrm{C}$ NMR spectrum of degraded fractions of JCS10.1N, according to monosaccharide composition, methylation results [1,20-27]. The anomeric resonances at 100.83 and $101.07 \mathrm{ppm}$ were assigned as the $\mathrm{C} 1$ of 1,4- and 1,4,6-linked $\alpha$-Glcp, respectively. The anomeric resonances at 99.80, 99.22, and $102.93 \mathrm{ppm}$ were assigned as the $\mathrm{C} 1$ of T-Glcp, 1,4-Xylp, and 1,4-Manp, respectively. While the anomeric resonances at 109.08 and 107.44 ppm were assigned as the $\mathrm{C} 1$ of T-Araf at different chemical locations. In the ${ }^{1} \mathrm{H}$ NMR spectrum, the signals at 5.46 and $5.42 \mathrm{ppm}$ were assigned to the anomeric H-1 of 1,4- and 1,4,6-linked $\alpha$-Glcp, respectively according to their correlation with the anomeric carbons at 100.83 and $101.07 \mathrm{ppm}$, respectively in the HSQC (Figure 3B). Similarly, the signals at 4.55, 5.03 , and $5.14 \mathrm{ppm}$ were ascribed to the $\mathrm{H}-1$ of 1,4-linked $\beta$-Manp, terminal $\alpha$-Glcp, and 1,4-linked $\alpha$-Xylp, respectively (Figure 3A). The resonances at 5.11 and $5.24 \mathrm{ppm}$ were attributed to the anomeric hydrogen of terminal $\alpha$-Araf at different chemical locations. The other resonances were also assigned, and the chemical shifts corresponding to $\mathrm{H} 2$ to $\mathrm{H} 5$ or $\mathrm{H} 6$ of all the residues are listed in Table 2.
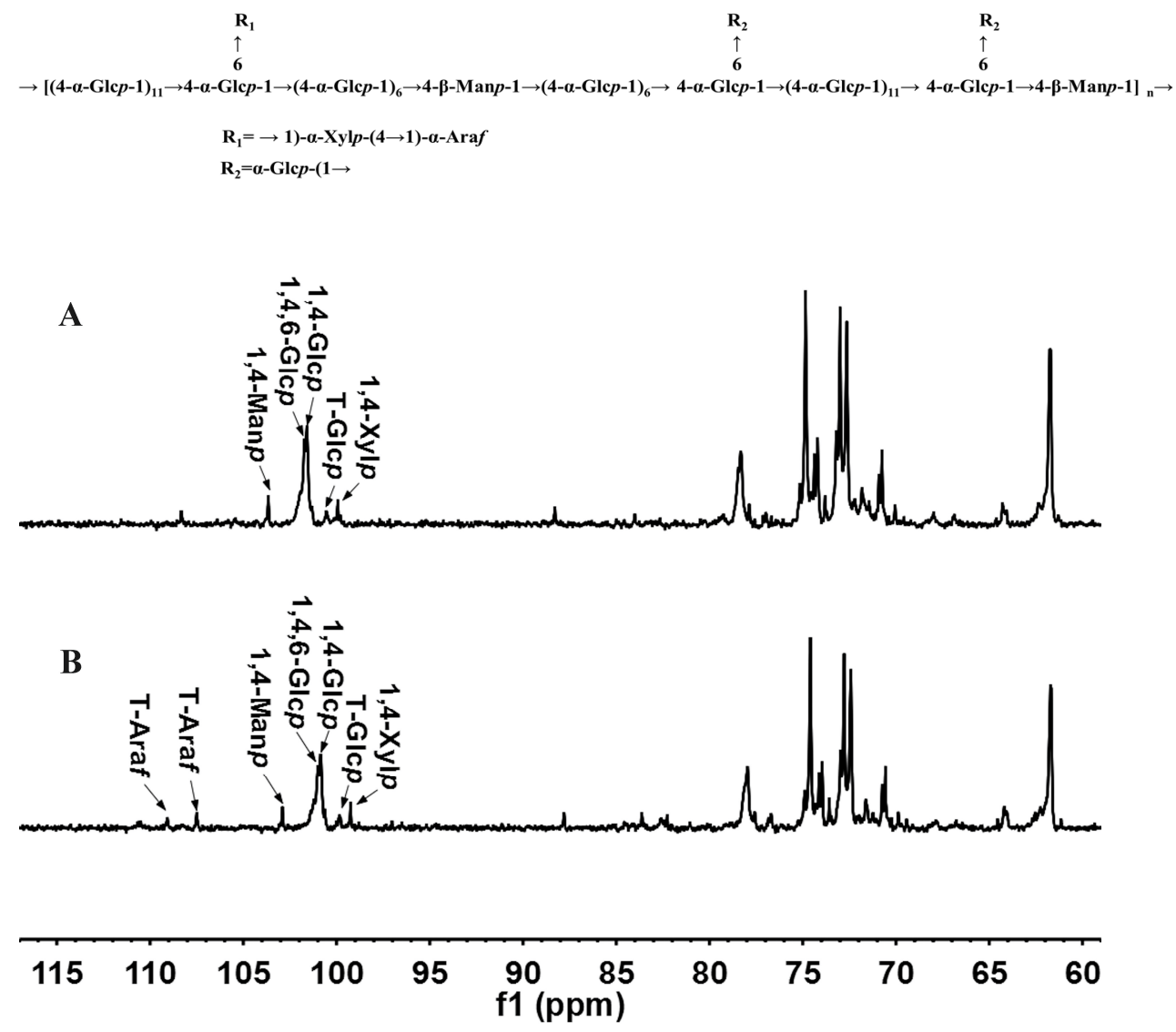

Figure 2. ${ }^{13} \mathrm{C}$ nuclear magnetic resonance (NMR) spectra of JCS1 polysaccharide and its degraded polysaccharide JCS10.1N. ${ }^{13}$ C NMR spectrum of (A) JCS10.1N and (B) JCS1. 
Table 2. Proton $\left({ }^{1} \mathrm{H}\right)$ and ${ }^{13} \mathrm{C}$ nuclear magnetic resonance (NMR) spectral assignments for JCS1 (ppm).

\begin{tabular}{|c|c|c|c|c|c|c|c|}
\hline \multicolumn{2}{|c|}{ Residues } & \multirow{3}{*}{$\begin{array}{c}\mathbf{1} \\
5.46 \\
100.83\end{array}$} & \multirow{3}{*}{$\begin{array}{c}\mathbf{2} \\
3.71 \\
72.75\end{array}$} & \multirow{3}{*}{$\begin{array}{c}3 \\
4.02 \\
74.53\end{array}$} & \multirow{3}{*}{$\begin{array}{c}\mathbf{4} \\
3.72 \\
78.02\end{array}$} & \multirow{3}{*}{$\begin{array}{c}\mathbf{5} \\
3.73 \\
72.45\end{array}$} & \multirow{3}{*}{$\begin{array}{c}\mathbf{6} \\
3.90 \\
61.57\end{array}$} \\
\hline $14_{-} \alpha_{-} C l_{C n}$ & $\mathrm{H}$ & & & & & & \\
\hline $1,4-\alpha-\mathrm{GIC} p$ & $\mathrm{C}$ & & & & & & \\
\hline \multirow{2}{*}{ T- $\alpha$-Glc $p$} & $\mathrm{H}$ & 5.03 & 3.68 & 3.83 & 3.49 & 3.79 & 3.90 \\
\hline & $\mathrm{C}$ & 99.80 & 71.94 & 74.06 & 69.84 & 72.76 & 61.65 \\
\hline \multirow{2}{*}{$1,4,6-\alpha$-Glc $p$} & $\mathrm{H}$ & 5.42 & 3.69 & 4.00 & 3.72 & 3.99 & $3.72 / 4.02$ \\
\hline & $\mathrm{C}$ & 101.07 & 71.46 & 73.50 & 78.02 & 74.93 & 70.40 \\
\hline \multirow{2}{*}{$1,4-\beta-\operatorname{Man} p$} & $\mathrm{H}$ & 4.55 & 3.36 & 3.85 & 3.72 & 3.84 & 3.75 \\
\hline & $\mathrm{C}$ & 102.93 & 73.95 & 73.61 & 77.58 & 71.51 & 64.09 \\
\hline \multirow{2}{*}{$1,4-\alpha-\mathrm{Xyl} p$} & $\mathrm{H}$ & 5.14 & 3.68 & 3.71 & 3.72 & 3.72 & - \\
\hline & $\mathrm{C}$ & 99.22 & 73.61 & 73.02 & 76.70 & 61.25 & - \\
\hline \multirow{2}{*}{ T- $\alpha$-Araf } & $\mathrm{H}$ & 5.11 & 4.20 & 4.03 & 4.12 & 3.46 & - \\
\hline & $\mathrm{C}$ & 109.08 & 82.57 & 76.66 & 83.56 & 64.07 & - \\
\hline \multirow{2}{*}{ T- $\alpha$-Araf } & $\mathrm{H}$ & 5.24 & 4.26 & nd & nd & nd & - \\
\hline & $\mathrm{C}$ & 107.44 & nd & nd & nd & nd & - \\
\hline
\end{tabular}

In the HMBC spectrum (Figure 3C), the cross peak A ( $8101.07 / \delta 3.72)$ represented the correlation between C-1 of 1,4,6-linked $\alpha$-Glc $p$ and H-4 of the 1,4-linked $\alpha$-Glc $p$. The cross peak B $(\delta 78.02 / \delta 5.42)$ represented the correlation between the C-4 of 1,4-linked $\alpha$-Glcp and H-1 of 1,4,6-linked $\alpha$-Glc $p$. The cross peak $C(\delta 102.93 / \delta 3.72)$ showed the correlation between the $C-1$ of 1,4 -linked $\beta$-Man $p$ and $\mathrm{H}-4$ of 1,4-linked $\alpha$-Glcp. The cross peak D $(\delta 78.02 / \delta 4.55)$ showed the correlation between the C-4 of 1,4-linked $\alpha$-Glc $p$ and H-1 of 1,4-linked $\beta$-Man $p$. The cross peak E $(\delta 100.83 / \delta 3.72)$ indicated the correlation of the C-1 of 1,4-linked $\alpha$-Glcp and H-4 of 1,4-linked $\beta$-Man $p$. The cross peak F ( $\delta 5.46 / \delta 77.58)$ represented the correlation between the H-1 of 1,4-linked $\alpha$-Glc $p$ and C-4 of 1,4-linked $\beta$-Manp. The cross peak G ( $83.72 / \delta 101.07)$ indicated the correlation of the H-4 of 1,4-linked $\beta$-Man $p$ and $\mathrm{C}-1$ of $1,4,6$-linked $\alpha$-Glc $p$. The cross peak $\mathrm{H}(\delta 77.58 / \delta 5.42)$ showed the correlation between $\mathrm{C}-4$ of 1,4-linked $\beta$-Man $p$ and H-1 of 1,4,6-linked $\alpha$-Glc $p$. The cross peak I $(\delta 100.83 / \delta 3.72)$ represented the correlation between the C-1 of 1,4-linked $\alpha$-Glc $p$ and H-4 of 1,4,6-linked $\alpha$-Glc $p$. The cross peak J ( $\delta 5.46 / \delta 78.02)$ represented the correlation between H-1 of 1,4-linked $\alpha$-Glc $p$ and C-4 of 1,4,6-linked $\alpha$-Glc $p$. The cross peak K ( $899.22 / \delta 3.72)$ represented the correlation between the C-1 of 1,4-linked $\alpha$-Xylp and H-6 of 1,4,6-linked $\alpha$-Glcp. The cross peak L $(\delta 5.14 / \delta 70.40)$ showed the correlation between the H-1 of 1,4-linked $\alpha$-Xylp and C- 6 of 1,4,6-linked $\alpha$-Glcp. The cross peak M $(\delta 5.03 / \delta 70.40)$ showed the correlation between the H-1 of T- $\alpha$-Glcp and C-6 of 1,4,6-linked $\alpha$-Glc $p$. The cross peak N ( $\delta 99.80 / \delta 4.02)$ indicated the correlation of the C-1 of T- $\alpha$-Glcp and H-6 of 1,4,6-linked $\alpha$-Glcp. The cross peak O $(\delta 107.44 / \delta 3.72)$ showed the correlation between C-1 of T- $\alpha$-Araf and H-4 of 1,4-linked $\alpha$-Xylp. The cross peak P $(\delta 5.24 / \delta 76.70)$ indicated the correlation of H-1 of T- $\alpha$-Araf and C-4 of 1,4-linked $\alpha$-Xylp. The cross peak Q $(\delta 109.08 / \delta 3.72)$ showed the correlation between C-1 of T- $\alpha$-Ara $f$ at different chemical locations and $\mathrm{H}-4$ of 1,4-linked $\alpha$-Xylp. According to the above results, the backbone of JCS1 might consist of repeated 1,4-linked $\beta$-Man $p$ and 1,4-linked $\alpha$-Glc $p$ units with branches at the C-6 of 1,4-linked $\alpha$-Glc $p$ substituted by 1,4-linked $\alpha$-Xylp and T- $\alpha$-Araf linked at C-4 of 1,4-linked $\alpha$-Xylp. The other branches might be linked by T- $\alpha$-Glc $p$ at C-6 of 1,4-linked $\alpha$-Glc $p$. Based on the monosaccharide analysis, methylation, partial hydrolysis, and NMR analysis, a possible repeating unit for JCS1 was proposed as follows: 
A

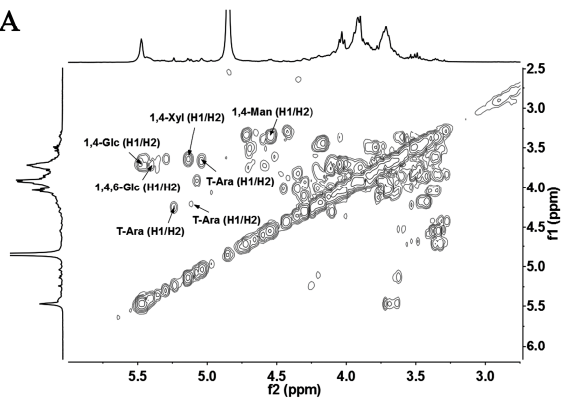

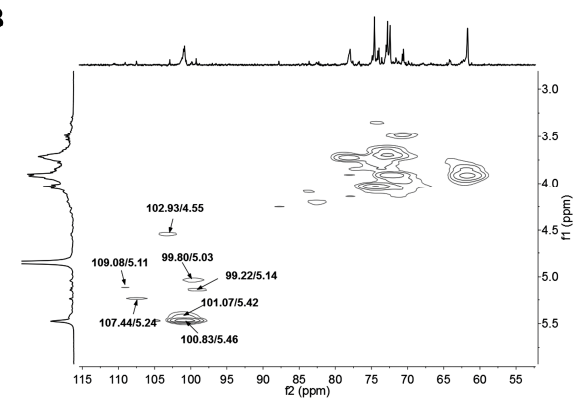

C

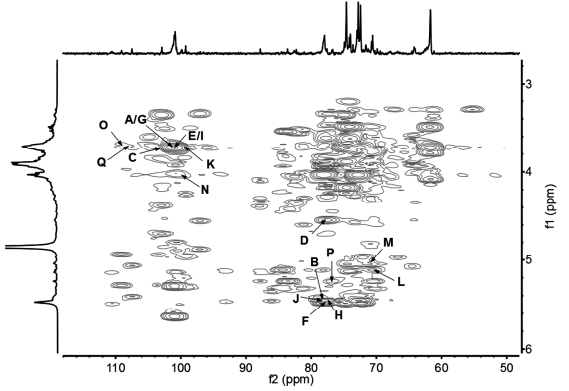

Figure 3. Two-dimensional spectra of JCS1. (A) Proton $\left({ }^{1} \mathrm{H}\right)-{ }^{1} \mathrm{H}$ correlation spectroscopy (COSY); (B) heteronuclear single-quantum correlation (HSQC); and (C) heteronuclear nuclear multi-bond correlation HMBC spectra.

\subsection{YJCS1 Induces Neurite Extension of PC-12 Cells}

Considerable research has been carried out to investigate the antioxidant and immunomodulatory activity of acetyl derivatives of polysaccharides [24,28,29]. The acetylation (DS) of YJCS1 was 0.025 while the average molecular weight was $18.8 \mathrm{kDa}$.

Interestingly, we found that JCS1 did not extend the neurites of the PC-12 cells; however, the induction of the PC-12 cells was observed to be in a dose-dependent manner following treatment with the acetyl derivative of JCS1. The induced neuritogenesis was significant at low and high concentrations (Figure 4F,H). The results suggested that this acetylated polysaccharide had the potential to be developed as a drug candidate to prevent or even treat neurodegeneration diseases.
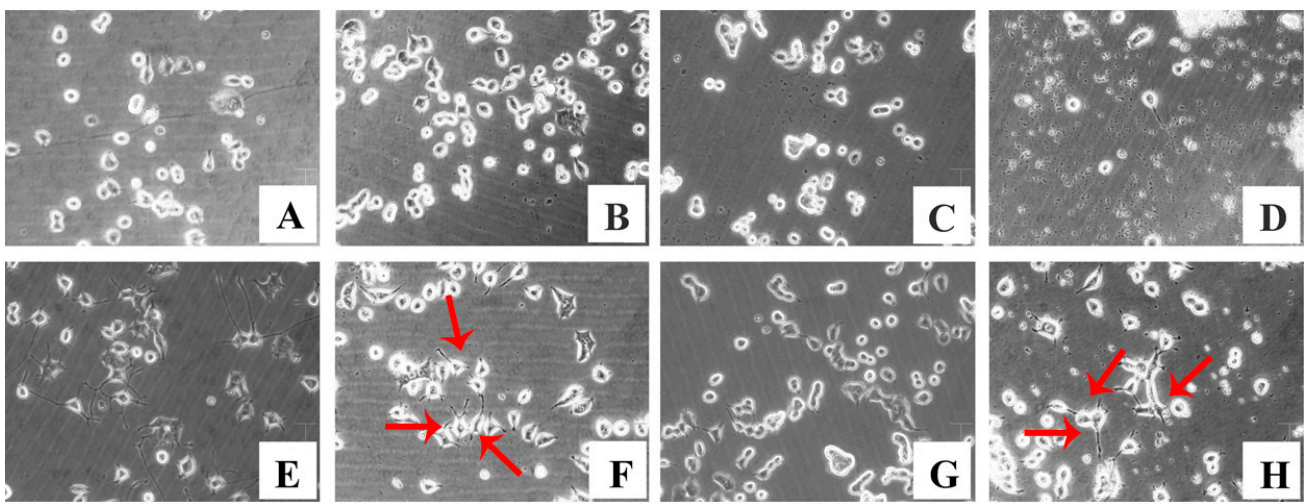

$\overline{\operatorname{Bar}}=200 \mu \mathrm{m}$

Figure 4. The PC-12 cells were treated with (A) normal medium or with different concentrations of polysaccharide JCS1; (B) 5.56; (C) 33.33; and (D) $55.56 \mu \mathrm{M}$ for $120 \mathrm{~h}$; (E) PC-12 cells treated with nerve growth factor (NGF) as a positive control; (F-H) PC-12 cells incubated with YJCS1 at three different concentrations; (F) 5.56; (G) 33.33; and (H) $55.56 \mu \mathrm{M}$. Represented positive neuritogenesis induced by YJCS1 was indicated by red arrows. 


\section{Discussion}

In recent decades, differences have been discovered in the molecular weight, category, and molecular ratios of monosaccharide linkage types of polysaccharides extracted from Dendrobium plant species. However, there might be some common structural characteristics among Dendrobium plant polysaccharides. For example, 1,3- and 1,4-linked mannose residues are usually in the $\beta$ configuration [1,23,30-32] while 1,2- and 1,6-linked mannose residues are in the $\alpha$ configuration [23,32]. Most galactose residues are terminal linkages, which are in the $\alpha$ configuration $[1,4,23]$. Few 1,3and 1,6-linked galactose residues are the backbone [3,4]. Glucose residues are 1,4- and 1,6-linked and are basically on the backbone [1,4,23,30-32]. In addition, all kinds of Dendrobium have neutral polysaccharides [1,3,4,23,30-32], but interestingly, no studies have reported that Dendrobium has pectic polysaccharide [2]. This is likely because most Dendrobium polysaccharides have been extracted from its stems, which have a lower acidic polysaccharide content than that of the fruit body and flowers. Furthermore, the monosaccharide composition of a few homogeneous polysaccharides consists of low quantities of arabinose and xylose. Both of these two residues are on the branches [2,27].

Based on the structure-activity relationship analysis, the diverse structural characteristics of Dendrobium polysaccharides have resulted in various bioactivities. The first detected bioactivity of polysaccharides from Dendrobium officinale was an immunomodulatory activity [33]. Other kinds of Dendrobium polysaccharides were also discovered to have immunostimulatory properties [1-3,23-32]. In addition, some researchers have focused on the antioxidant and antitumor activities.

DCPP1a-1, isolated from the suspension-cultured protocorms of Dendrobium significantly inhibited hydroxyl radicals and superoxide anion radicals [34]. In another study [26], mice injected intraperitoneally with Dendrobium denneanum polysaccharide for 20 days showed lower serum malondialdehyde (MDA) and higher serum superoxide dismutase (SOD) than the control mice did. Some polysaccharides inhibit tumor cell growth in vitro [35] and in vivo [33,36]. The researchers considered the antitumor properties to be associated with the excellent immune-enhancing and antioxidant properties of the polysaccharide [33]. Moreover, considerable research has been focused on studying other bioactivities of dendrobium polysaccharides. For instance, the DCLP polysaccharide isolated from Dendrobium chrysotoxum had antidiabetic effects in alloxan-induced hyperglycemic mice [37]. In addition, the DHP-W2 polysaccharide from Dendrobium huoshanense might impede anti-glycation activity [27].

Currently, some acetylated polysaccharides from Dendrobium have been reported [1,2,23,30,31]. These polysaccharides were extracted from D. nobile, D. officinale, and D. huoshanense. The substitution position of their acetyl groups differed, and all the acetylated Dendrobium polysaccharides had bioactivities. It was observed that the acetyl groups were just substituted at the O-2 or O-3 of glucose and mannose $[1,23,30,31]$. Similarly, considerable research has shown that acemannan, an acetylated polymannose from Aloe vera, promoted tissue repair [38,39]. Furthermore, some investigations were carried out on the acemannan to determine the effect of the acetyl-groups on its physical and biological properties [40,41]. Previous studies have demonstrated the important role of acetyl groups on polysaccharide bioactivity [40]. The above research studies have provided two enlightening pieces of information or questions. One is that the bioactivities are different between the native active Dendrobium polysaccharides with acetyl groups and those without acetyl groups, which were deacetylated. Another important question is whether acetylated derivatives of novel Dendrobium polysaccharides, which mainly contain glucose or mannose have novel bioactivities. Therefore, in this study, the novel polysaccharide containing abundant glucose extracted from D. nobile was acetylated. Moreover, the acetylated polysaccharide, YJCS1, induced the neuritogenesis of PC-12 cells, which provides a reference for studying novel bioactivities of acetylated derivatives of Dendrobium polysaccharides.

Acknowledgments: This work was supported by grants from the Project of the Shanghai Committee of Science and Technology (15495800300), the State Key Program of National Natural Science Foundation of China (31230022), 
the Program of Shanghai Subject Chief Scientist (16XD1404500), and the National Natural Science Foundation of China (NSFC, 31670814).

Author Contributions: Can Jin conceived, designed, and performed the experiments and wrote the paper; Zhenyun Du carried out the bioactivity test; Liyan Lin, Lishuang Zhou, and Saijuan Li analyzed the data; Qin Liu contributed reagents/materials/analysis tools; and Kan Ding designed the project and revised the paper.

Conflicts of Interest: The authors declare no conflict of interest.

\section{References}

1. Wang, J.H.; Zha, X.Q.; Luo, J.P.; Yang, X.F. An acetylated galactomannoglucan from the stems of Dendrobium nobile Lindl. Carbohydr. Res. 2010, 345, 1023-1027. [CrossRef] [PubMed]

2. Wang, J.H.; Luo, J.P.; Zha, X.Q. Structural features of a pectic polysaccharide from the stems of Dendrobium nobile Lindl. Carbohydr. Polym. 2010, 81, 1-7. [CrossRef]

3. Wang, J.H.; Luo, J.P.; Yang, X.F.; Zha, X.Q. Structural analysis of a rhamnoarabinogalactan from the stems of Dendrobium nobile Lindl. Food Chem. 2010, 122, 572-576. [CrossRef]

4. Luo, A.; He, X.; Zhou, S.; Fan, Y.; He, T.; Chun, Z. In vitro antioxidant activities of a water-soluble polysaccharide derived from Dendrobium nobile Lindl. Extracts. Int. J. Biol. Macromol. 2009, 45, 359-363. [CrossRef] [PubMed]

5. Wang, J.H.; Luo, J.P.; Zha, X.Q.; Feng, B.J. Comparison of antitumor activities of different polysaccharide fractions from the stems of Dendrobium nobile Lindl. Carbohydr. Polym. 2010, 79, 114-118. [CrossRef]

6. Pan, L.H.; Li, X.F.; Wang, M.N.; Zha, X.Q.; Yang, X.F.; Liu, Z.J.; Luo, Y.B.; Luo, J.P. Comparison of hypoglycemic and antioxidative effects of polysaccharides from four different Dendrobium species. Int. J. Biol. Macromol. 2014, 64, 420-427. [CrossRef] [PubMed]

7. Xu, J.; Liu, W.; Yao, W.; Pang, X.; Yin, D.; Gao, X. Carboxymethylation of a polysaccharide extracted from ganoderma lucidum enhances its antioxidant activities in vitro. Carbohydr. Polym. 2009, 78, 227-234. [CrossRef]

8. Qin, T.; Chen, J.; Wang, D.; Hu, Y.; Zhang, J.; Wang, M.; Qiu, S.; Gao, Z.; Liu, R.; Yu, Y.; et al. Selenylation modification can enhance immune-enhancing activity of Chinese angelica polysaccharide. Carbohydr. Polym. 2013, 95, 183-187. [CrossRef] [PubMed]

9. Zhang, N.; Chen, H.; Ma, L.; Zhang, Y. Physical modifications of polysaccharide from Inonotus obliquus and the antioxidant properties. Int. J. Biol. Macromol. 2013, 54, 209-215. [CrossRef] [PubMed]

10. Zhao, B.; Zhang, J.; Yao, J.; Song, S.; Yin, Z.; Gao, Q. Selenylation modification can enhance antioxidant activity of Potentilla anserina L. polysaccharide. Int. J. Biol. Macromol. 2013, 58, 320-328. [CrossRef] [PubMed]

11. Chen, Y.; Zhang, H.; Wang, Y.; Nie, S.; Li, C.; Xie, M. Acetylation and carboxymethylation of the polysaccharide from Ganoderma atrum and their antioxidant and immunomodulating activities. Food Chem. 2014, 156, 279-288. [CrossRef] [PubMed]

12. Xie, J.H.; Zhang, F.; Wang, Z.J.; Shen, M.Y.; Nie, S.P.; Xie, M.Y. Preparation, characterization and antioxidant activities of acetylated polysaccharides from Cyclocarya paliurus leaves. Carbohydr. Polym. 2015, 133, 596-604. [CrossRef] [PubMed]

13. Liu, X.X.; Wan, Z.J.; Shi, L.; Lu, X.X. Preparation and antiherpetic activities of chemically modified polysaccharides from polygonatum cyrtonema hua. Carbohydr. Polym. 2011, 83, 737-742. [CrossRef]

14. Zeng, H. Investigation on Preparation of Acemannan Analogy by Molecular Modification of KGM and Its Bioactivity. Master's Thesis, Jiangnan University, Wuxi, China, 2006. (In Chinese)

15. Wang, H.J.; Shi, S.S.; Bao, B.; Li, X.J.; Wang, S.C. Structure characterization of an arabinogalactan from green tea and its anti-diabetic effect. Carbohydr. Polym. 2010, 81, 1-7. [CrossRef]

16. Needs, P.W.; Selvendran, R.R. Avoiding oxidative-degradation duringsodium-hydroxide methyl iodide-mediated carbohydrate methylation indimethyl-sulfoxide. Carbohydr. Res. 1993, 245, 1-10. [CrossRef]

17. Lowry, O.; Rosebrough, N.; Farr, L.; Randall, R. Protein measurement with the Folin phenol reagent. J. Biol. Chem. 1951, 193, 265-275. [PubMed]

18. Blumenkrantz, N.; Asboehansen, G. New method for quantitative determination of uronic acids. Anal. Biochem. 1973, 54, 484-489. [CrossRef] 
19. Zhang, Z.; Zhang, Q.; Wang, J.; Song, H.; Zhang, H.; Niu, X. Chemical modification and influence of function groups on the in vitro-antioxidant activities of porphyran from porphyra haitanensis. Carbohydr. Polym. 2010, 79, 290-295. [CrossRef]

20. Zheng, C.; Dong, Q.; Chen, H.; Cong, Q.; Ding, K. Structural characterization of a polysaccharide from chrysanthemum morifolium flowers and its antioxidant activity. Carbohydr. Polym. 2015, 130, $113-121$. [CrossRef] [PubMed]

21. Wang, P.; Liao, W.; Fang, J.; Liu, Q.; Yao, J.; Hu, M.; Ding, K. A glucan isolated from flowers of Lonicera japonica Thunb. Inhibits aggregation and neurotoxicity of abeta42. Carbohydr. Polym. 2014, 110, 142-147. [CrossRef] [PubMed]

22. Chen, X.; Cao, D.; Zhou, L.; Jin, H.; Dong, Q.; Yao, J.; Ding, K. Structure of a polysaccharide from Gastrodia elata Bl., and oligosaccharides prepared thereof with anti-pancreatic cancer cell growth activities. Carbohydr. Polym. 2011, 86, 1300-1305. [CrossRef]

23. Zha, X.Q.; Luo, J.P.; Luo, S.Z.; Jiang, S.T. Structure identification of a new immunostimulating polysaccharide from the stems of Dendrobium huoshanense. Carbohydr. Polym. 2007, 69, 86-93. [CrossRef]

24. Dey, B.; Bhunia, S.K.; Maity, K.K.; Patra, S.; Mandal, S.; Maiti, S.; Maiti, T.K.; Sikdar, S.R.; Islam, S.S. Chemical analysis of an immunoenhancing water-soluble polysaccharide of an edible mushroom, pleurotus florida blue variant. Carbohydr. Res. 2010, 345, 2736-2741. [CrossRef] [PubMed]

25. Dong, Q.; Yao, J.; Fang, J.N.; Ding, K. Structural characterization and immunological activity of two cold-water extractable polysaccharides from cistanche deserticola Y. C. Ma. Carbohydr. Res. 2007, 342, 1343-1349. [CrossRef] [PubMed]

26. Luo, A.; Ge, Z.; Fan, Y.; Luo, A.; Chun, Z.; He, X. In vitro and in vivo antioxidant activity of a water-soluble polysaccharide from Dendrobium denneanum. Molecules 2011, 16, 1579-1592. [CrossRef] [PubMed]

27. Pan, L.H.; Feng, B.J.; Wang, J.H.; Zha, X.Q.; Luo, J.P. Structural characterization and anti-glycation activity in vitro of a water-soluble polysaccharide from Dendrobium huoshanense. Int. J. Biol. Macromol. 2013, 37, 313-321.

28. Song, Y.; Yang, Y.; Zhang, Y.; Duan, L.; Zhou, C.; Ni, Y.; Liao, X.; Li, Q.; Hu, X. Effect of acetylation on antioxidant and cytoprotective activity of polysaccharides isolated from pumpkin (Cucurbita pepo, lady godiva). Carbohydr. Polym. 2013, 98, 686-691. [CrossRef] [PubMed]

29. Ma, L.; Chen, H.; Zhang, Y.; Zhang, N.; Fu, L. Chemical modification and antioxidant activities of polysaccharide from mushroom Inonotus obliquus. Carbohydr. Polym. 2012, 89, 371-378. [CrossRef] [PubMed]

30. Hua, Y.F.; Zhang, M.; Fu, C.X.; Chen, Z.H.; Chan, G.Y. Structural characterization of a 2-O-acetylglucomannan from Dendrobium officinale stem. Carbohydr. Res. 2004, 339, 2219-2224. [CrossRef] [PubMed]

31. Hsieh, Y.S.; Chien, C.; Liao, S.K.; Liao, S.F.; Hung, W.T.; Yang, W.B.; Lin, C.C.; Cheng, T.J.; Chang, C.C.; Fang, J.M.; et al. Structure and bioactivity of the polysaccharides in medicinal plant Dendrobium huoshanense. Bioorg. Med. Chem. 2008, 16, 6054-6068. [CrossRef] [PubMed]

32. Li, Q.; Xie, Y.; Su, J.; Ye, Q.; Jia, Z. Isolation and structural characterization of a neutral polysaccharide from the stems of Dendrobium densiflorum. Int. J. Biol. Macromol. 2012, 50, 1207-1211. [CrossRef] [PubMed]

33. Cai, T.Y.; Liu, Q.L.; Li, D.; Chen, A.Z.; Huang, B.H.; Cheng, S.J. Effects of Dendrobium officinale polysaccharides on the activities of T lymphocytes and macrophages. J. Sun Yat-Sen Univ. Med. Sci. 1989, 10, 66-67.

34. He, T.G.; Yang, L.T.; Li, Y.R.; Wang, C.Q.; Hu, J.S. Effects of the polysaccharides DCPP1a-1 from suspension-cultured protocorms of Dendrobium candidum on oxygenradical and lipid peroxidation. Nat. Prod. Res. Dev. 2007, 19, 410-414.

35. Luo, A.X.; Fan, Y.J. Immune stimulating activity of water-soluble polysaccharide fractions from Dendrobium nobile Lindl. Afr. J. Pharm. Pharmacol. 2011, 5, 625-631. [CrossRef]

36. Fan, Y. Evaluation of anti-tumor activity of water-soluble polysaccharides from Dendrobium denneanum. Afr. J. Pharm. Pharmacol. 2011, 5, 415-420. [CrossRef]

37. Zhao, Y.P.; Son, Y.O.; Kim, S.S.; Jang, Y.S.; Lee, J.C. Antioxidant and anti-hyperglycemic activity of polysaccharide isolated from Dendrobium chrysotoxum Lindl. J. Biochem. Mol. Biol. 2007, 40, 670-677. [CrossRef] [PubMed]

38. Xing, W.; Guo, W.; Zou, C.H.; Fu, T.T.; Li, X.Y.; Zhu, M.; Qi, J.H.; Song, J.; Dong, C.H.; Li, Z.; et al. Acemannan accelerates cell proliferation and skin wound healing through akt/mtor signaling pathway. J. Dermatol. Sci. 2015, 79, 101-109. [CrossRef] 
39. Jettanacheawchankit, S.; Sasithanasate, S.; Sangvanich, P.; Banlunara, W.; Thunyakitpisal, P. Acemannan stimulates gingival fibroblast proliferation; expressions of keratinocyte growth factor-1, vascular endothelial growth factor, and type i collagen; and wound healing. J. Pharmacol. Sci. 2009, 109, 525-531. [CrossRef] [PubMed]

40. Zheng, L.Y.; Zhu, J.F. Study on antimicrobial activity of chitosan with different molecular weights. Carbohydr. Polym. 2003, 54, 527-530. [CrossRef]

41. Chokboribal, J.; Tachaboonyakiat, W.; Sangvanich, P.; Ruangpornvisuti, V.; Jettanacheawchankit, S.; Thunyakitpisal, P. Deacetylation affects the physical properties and bioactivity of acemannan, an extracted polysaccharide from aloe vera. Carbohydr. Polym. 2015, 133, 556-566. [CrossRef] [PubMed]

2017 by the authors. Licensee MDPI, Basel, Switzerland. This article is an open access article distributed under the terms and conditions of the Creative Commons Attribution (CC BY) license (http://creativecommons.org/licenses/by/4.0/). 